practice. Some of these have already been implemented, notably Professional Standards Review Organisations (PSROs). And, though PSROs have made no perceptible impact on containing costs, other proposals for the administrative regulation of health care are being discussed. Indeed, the basic dilemma of health policy-making in the United States is how to improve medical care without at the same time giving the health-care providers an open cheque on public funds. This problem does not arise in the case of the NHS with its fixed budgets. Hence the paradox that a nationalised health service seems to be able to offer great autonomy to doctors (within the constraints of the available funds) than a free market system.

The American dilemma suggests two conclusions relevant for Britain. Firstly, sooner or later all health care systems come up against limitations of finance, for even the United States has to recognise the need to ration scarce resources. ${ }^{5}$ Secondly, the medical profession has a special responsibility for helping to find a solution for this problem. If it ducks the challenge, to judge from the experience in the USA, there will be increasing political and administrative pressure designed to regulate its day-to-day activities. The price of professional freedom is clinical self-restraint.

${ }^{1}$ Marmor, T R, Rethinking National Health Insurance, p 73. The Public Interest No 46, 1977.

${ }^{2}$ Enthoven, A C, New England fournal of Medicine, 1978, 298, 650.

3 Congressional Budget Office, Expenditures for Health Care. Washington DC, Government Printing Office, 1977.

4 Wilson, R W, and White, E L, Medical Care, 1977, 15, 636

5 Fuchs, V R, Who shall live? New York, Basic Books, 1974.

\section{Vitreous haemorrhage}

Diabetic retinopathy has become one of the most important causes of blindness. One way in which vision may be impaired is through haemorrhage into the vitreous humour. Vitreous haemorrhage may also be associated with retinal tears, systemic hypertension, trauma, vascular accidents in patients on anticoagulants, central vein occlusion, and occasionally inflammatory disease.

The fate of blood in the vitreous is poorly understood. On some occasions it may clear within a few weeks, but on others it may take years to do so. The vitreous may appear to be full of a suspension of red blood cell ghosts (erythroclasts), or membranes may develop; and, to complicate the picture still further, blood lying between the retina and the vitreous (subhyaloid or preretinal haemorrhage) may remain liquid and may be seen to move when the patient changes posture. The surgeon can often see these variations, but the recent development of ultrasound techniques has given him a clearer indication of the nature and site of the haemorrhage or membrane. ${ }^{1}$

Two quite different methods of treatment are available to the patient with an established haemorrhage which shows no signs of spontaneous clearance within a reasonable time. Firstly, the surgical approach has been the centre of great interest in the last decade. Machemer and Parel ${ }^{2}$ developed an instrument, which could be passed into the vitreous via the pars plana, designed to cut vitreous gel and membranes and remove these by suction. At the same time the vitreous was replaced with clear fluid. Since then there has been a great proliferation of instruments and no clear favourite has yet emerged, which shows that every one has certain problems as well as merits. Surgery with these instruments demands considerable skill and training, particularly in microsurgical techniques; but it has resulted in good success rates. ${ }^{3}$ The exceptions have most often been in diabetic patients, in whom $\underline{T}$ there are often problems from other aspects of retinopathy (such as secondary retinal detachment) which may have $\stackrel{\mathbb{D}}{\mathcal{Q}}$

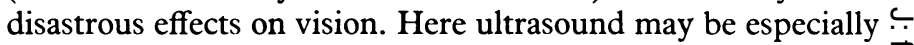
valuable in alerting the surgeon to the presence of multiple $\underset{\vec{g}}{\vec{g}}$ abnormalities.

The second and totally different approach is injection of $\frac{\text { C }}{0}$ urokinase. This enzyme's fibrinolytic action is known to work $\frac{\bar{m}}{\frac{5}{\sigma}}$ well in cases of recent haemorrhage and clots in the anterior $\mathbb{Q}$ chamber. Williamson and Forrester ${ }^{4}$ first reported its use to clear long-standing vitreous haemorrhage in a diabetic patient; $\vec{\theta}$ they injected 5000 units of urokinase in $1.5 \mathrm{ml}$ of distilled water. This quantity of fluid cannot be injected into the vitreous $\vec{\omega}$ cavity without aspirating a similar volume of vitreous humour $\frac{\partial}{\partial}$ -immediately raising a doubt whether improvement is due to the enzyme or simply to the exchange of the vitreous. Never- $\overrightarrow{\dot{s}}$ theless, subsequent work using much less fluid suggested that the exchange element is probably unimportant. ${ }^{5}$ Now that several larger series have been published the Glasgow group has $\stackrel{f}{\circ}$ reported very favourable results, ${ }^{6}$ but some other workers $ᄋ$ have been less successful. ${ }^{78}$

There is little evidence that a long-standing vitreous $\vec{F}$ haemorrhage contains true clots, so that the mode of action $\frac{D}{2}$ of the enzyme remains obscure. Removal of a suspension of red cell ghosts was readily understandable when there was a large vitreous exchange; but this has not been the case in recent series. It is hard to conceive how dense membranes could be removed or dissolved by the chemical action of urokinase. In several cases the benefit has been delayed several weeks or even months after injection of the enzyme, again $\stackrel{\varnothing}{\varnothing}$ suggesting that its fibrinolytic activity may not be relevant. $\stackrel{2}{\Rightarrow}$ Despite recent studies ${ }^{9}$ on the mechanism of its action by some $\frac{\hat{O}}{3}$ of the original workers, the question remains unanswered.

Nevertheless, as is shown by a new report ${ }^{10}$ on the use of urokinase injections from Australia, there is no question that the treatment can be effective. Thirty-four eyes were treated, with substantial improvement in vision in 19. The high cost of the enzyme is a drawback, but the technique is simple, and the Australian report concludes that injection of urokinase should $\dot{\delta}$ now be the first line of treatment for long-standing vitreous haemorrhage, with surgical intervention reserved for those $\frac{9}{7}$ cases which do not respond.

Certainly the result of this group and the continuing success $\rightarrow$ of the original Glasgow workers dictate that this simple technique should receive further evaluation. Possibly detailed $\tilde{\sim}$ ultrasound studies may help to show which type of N haemorrhage responds to the injection of the enzyme and $\overline{0}$ which type can be removed only surgically.

1 Restori, M, and McLeod, D, Transactions of the Ophthalmological Societies of the United Kingdom, 1977, 97, 232.

${ }^{2}$ Machemer, R, Parel, M, and Buettner, H, American fournal of Ophthalmology, 1972, 73, 1.

3 Boase, D L, et al, Transactions of the Ophthalmological Societies of the $\frac{\stackrel{\mathrm{Q}}{\mathbb{D}}}{\mathrm{Q}}$ United Kingdom, 1977, 97, 251.

4 Williamson, J, and Forrester, J V, Lancet, 1972, 2, 488.

5 Dugmore, W M, and Raichand, M, American fournal of Ophthalmology, $1973,75,779$.

${ }^{6}$ Forrester, J V, and Williamson, J, Transactions of the Ophthalmological 응 Societies of the United Kingdom, 1974, 94, 583.

${ }^{7}$ Holmes Sellors, P K, Kanski, J J, and Watson, D M, Transactions of the Ophthalmological Societies of the United Kingdom, 1974, 94, 591.

${ }^{8}$ Cleary, P E, et al, Transactions of the Ophthalmological Societies of the United Kingdom, 1974, 94, 587.

${ }^{9}$ Forrester, J V, et al, Experimental Eye Research, 1976, 22, 181.

10 Chapman-Smith, J S, and Crock, G W, British fournal of Ophthalmology, 1977, 61, 500. 